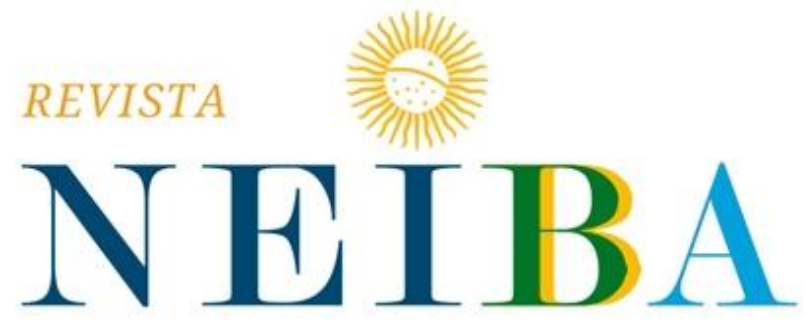

CADERNOS ARGENTINA-BRASIL

\title{
O RENTISMO NA AMÉRICA LATINA: A ECONOMIA POLÍTICA DA DÍVIDA PÚBLICA EM BRASIL E EQUADOR NO SÉCULO XXI
}

RENTISM IN LATIN AMERICA: THE POLITICAL ECONOMY OF PUBLIC DEBT IN BRAZIL AND ECUADOR IN THE 21STCENTURY

\section{Eduardo Santos Maia'}

1 Universidade Federal do Rio de Janeiro (UFRJ), Rio de Janeiro, RJ, Brasil. E-mail: eduardo.maia@live.com. ORCID: https://orcid.org/0000-0002-9347-8841.

Recebido em: 27 jan. 2019 | Aceito em: 20 set. 2019

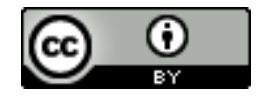

Esta obra está licenciado com uma Licença Creative Commons Atribuição 4.0 


\section{RESUMO}

Na década de 1970, a necessidade de circular o capital ocioso motivou ondas de empréstimos em massa para regiões acostumadas à escassez de crédito, como a América Latina, tendo como consequência o endividamento do subcontinente em moeda estrangeira e a "crise da dívida". No entanto, questiona-se que parte da dívida seja ilegal ou ilegítima, representando um mecanismo de transferência de renda das sociedades para o rentismo internacional. Diante deste cenário, o presente trabalho visa preencher lacunas existentes na temática da dívida pública. Inexistem, ao alcance dos esforços aqui empreendidos, pesquisas que trabalhem o assunto de forma comparada a partir de uma perspectiva internacional. Nesse sentido, tem-se por objetivo analisar comparativamente as posições de Brasil e Equador em relação ao pagamento de suas dívidas públicas no presente século. Para tanto, a pesquisa se utiliza de uma análise histórico-comparativa. Os resultados preliminares sugerem que a auditoria equatoriana possibilitou avanços sociais de caráter duradouro; enquanto no Brasil a opção pela continuidade no pagamento da dívida restringiu os caminhos disponíveis. Observa-se, assim, que embora de caráter predominantemente financeiro, a questão da dívida pública toca também em aspectos econômicos, políticos e sociais e é um dos elementos constritores do desenvolvimento e projeção dos países da América Latina.

Palavras-chave: Dívida pública; Brasil; Equador

\section{ABSTRACT}

In the 1970s, the need to circulate idle capital motivated waves of mass loans to regions used to scarcity of credit, such as Latin America, which had as consequence the rise of indebtedness in foreign currency and the "debt crisis". Nonetheless, it is argued that part of the debt is either illegal or illegitimate, representing a mechanism of income transfer from societies to international rentism. The present paper aims to fulfill existing gaps in the public debt subject. Papers on the subject in comparative ways from an international perspective could not be found to the extent of this research. The objective of the paper is to analyze comparatively the stances of Brazil and Ecuador regarding the payment of their public debts in the 21st century. In order to do so, the methodology is a historical- 
comparative analysis. The preliminary results suggest the Ecuadorian auditing allowed lasting social improvement in opposition to Brazil, in which the option for the continuity in the public debt payment narrowed the available paths. Therefore, one can observe that, although mainly financial, the public debt implicates in economical, political, and social aspects, being also one of the elements limiting the development and projection of the Latin America countries.

Keywords: Public Debt; Brazil; Ecuador 
INTRODUÇÃO

A dívida pública é uma instituição da vida econômica antiga como o Estado westfaliano, integrando o conjunto de instrumentos que financiam suas atividades. Gradativamente, os endividamentos contratuais (contratos de empréstimos) e mobiliários (títulos) do Estado se tornaram prática recorrente nos países capitalistas. A dívida pública surge originalmente dos déficits orçamentários dos governos. Quando as despesas do Estado são maiores que a receita a diferença é financiada através de nova dívida. Quando um Estado se endivida em sua moeda junto a residentes no próprio país ele contrai dívida interna; já o endividamento feito em moeda estrangeira junto a não-residentes é chamado dívida externa.

Seja interno ou externo, há aumento no endividamento do Estado quando há necessidade de "fechar a conta" ou se alavancar. Schonerwald e Vernengo (2007) avaliam que débitos e dívidas não são benéficos ou maléficos per se. Os autores entendem que seus méritos devem ser avaliados conforme o papel que cumprem no desenvolvimento de uma economia nacional. "Em outras palavras, se déficit e dívida promovem crescimento econômico e distribuição de renda justa, eles devem ser vistos como positivos" (Schonerwald e Vernengo 2007, p. 2, tradução nossa) ${ }^{1}$.

O presente trabalho visa preencher lacunas existentes na temática da dívida pública latino-americana. Inexistem, ao alcance dos esforços aqui empreendidos, pesquisas que trabalhem o assunto de forma comparada a partir de uma perspectiva internacional. Estudos econômicos e contábeis avaliam a dívida pública pela ótica econométrica, por sua sustentabilidade ou através de esquemas analíticos que desconsideram os aspectos políticos. Nesse sentido, pretende-se trabalhar na interseção entre as esferas política e econômica a fim de se produzir uma análise que contemple a multiplicidade de aspectos que compõem a questão.

O objetivo da pesquisa é evidenciar a primazia do rentismo na América Latina através da análise dos casos de Brasil e Equador e seus respectivos posicionamentos em relação

\footnotetext{
1 In other words, if deficits and debt promote economic growth, and equitable income distribution, they should be seen as positive.
} 
à dívida pública. Os países em questão foram escolhidos pela possibilidade de comparação entre uma política de ruptura e uma de continuidade em relação à dívida. Se, por um lado, o Equador foi capaz de conduzir mudanças na dinâmica de sua dívida pública; o Brasil permanece como arquétipo de Estado condicionado por sua posição submissa no sistema financeiro internacional.

Para tanto, o trabalho divide-se em quatro partes: 1) "prolegômenos históricos", onde a evolução da relação entre América Latina e dívida pública será abordada por uma perspectiva histórica; 2) "esquema analítico e apresentações conceituais", em que serão expostos a metodologia da pesquisa e o ferramental conceitual: 3) "Brasil e Equador no século XXI", com um breve voo panorâmico nos governos anteriores e a análise dos casos e comparação entre uma política de continuidade e outra de ruptura e; 4) "considerações finais", em que é feito um balanço do trabalho e são apresentadas limitações e perspectivas.

\section{PROLEGÔMENOS HISTÓRICOS}

Nos países da América Latina a realidade é um longo histórico de submissão ao peso do endividamento. Já na primeira metade do século XIX, durante os processos de independência, os recém-formados Estados nacionais recorreram ao endividamento externo tanto de maneira forçada, e.g. o caso brasileiro de assunção de dívidas portuguesas, como de maneira voluntária, e.g., os Estados que precisavam estruturar suas forças militares a fim de sustentar suas frágeis independências (Ziliotto, 2011).

A novidade da década de 1970 foi o fácil acesso ao mercado de crédito internacional, proporcionado pelo excesso de liquidez internacional, por sua vez, originado na necessidade de rentabilizar a ociosa massa de capital gerada nos países produtores de petróleo. Nessa conjuntura, as divisas geradas no Oriente Médio foram revertidas na forma de crédito para a América Latina por intermédio de bancos e instituições financeiras europeias e estadunidenses. Uma das consequências imediatas foi a 
possibilidade de alavancagem dos governos latino-americanos via expansão do investimento público.

Também foi de grande relevância a necessidade de autofinanciamento dos regimes militares, com destaque para os países do Cone Sul, que demandavam enormes quantias para manutenção do aparato repressivo, das estruturas militares e para satisfação de setores internos estratégicos e aliados. Brasil, Argentina, Chile e Equador, por exemplo, contraíram dívidas para financiar seus regimes ou projetos de retorno duvidoso. A avalanche de recursos resultou em crescimento econômico momentâneo, porém não sustentável, por não ter sido acompanhado das alterações necessárias na estrutura econômica.

O endividamento da região é paradigmático do que Eichengreen e Hausmann (1999) chamam de "pecado original". Os autores associam o endividamento em moeda estrangeira a uma fragilidade, cujas consequências extrapolam a esfera monetáriofinanceira, uma vez que sujeita tais Estados a flutuações de uma moeda sobre a qual não possuem gestão, bem como aumenta a influência dos detentores de títulos da dívida nas dinâmicas política e econômica nacionais.

O aumento das taxas de juros estadunidenses - principal índice de ajuste dos contratos de empréstimo, cuja maioria era devida em dólar - combinado à queda dos preços das commodities no fim da década de 1970 pôs fim ao breve ciclo de crédito barato. A combinação da explosão do custo das dívidas com a redução das divisas disponíveis para pagá-las lançou a América Latina na crise da dívida. Desde então, o cotidiano na região é a inversão de significativa parte do orçamento público para o pagamento da dívida pública, que não se traduz em melhoria da condição dos países devedores. O acelerado processo de financeirização² ocorrido a partir da década de 1980 acentua a materialidade da limitação do desenvolvimento e da subordinação da região pela via financeira. Das quatro estruturas de poder propostas por Strange (1988), a estrutura financeira passou a se destacar como mecanismo central na espoliação de

\footnotetext{
${ }^{2}$ Aqui se utiliza o conceito de Zwan (2014) que define a financeirização como uma rede de processos interrelacionados - econômicos, políticos, sociais, tecnológicos - através da qual o setor financeiro expande sua influência para além do mercado e da economia.
} 
recursos e conservação da inserção subalterna dos países da região no sistema internacional.

Na década de 1990, as políticas econômicas, monetárias e fiscais implementadas pelos países da América Latina estiveram vinculadas à lógica do Consenso de Washington. Isto é, na esteira da crise do keynesianismo estabeleceu-se o diagnóstico feito a partir da nova ideologia econômica dominante ${ }^{3}$ de que a crise latino-americana originou-se na indisciplina fiscal e no estatismo (Bresser-Pereira 1991, p. 5). Nesse sentido, as medidas adotadas pelos governos dialogaram com as diretrizes do Consenso; entre elas: 1 ) redução do déficit; 2) taxas de câmbio flexíveis, determinadas pelo mercado; 3) liberalização da economia; 4) retirada de restrições a investimentos; 5) privatizações (Williamson, 1990). Importante observar que o Consenso de Washington não lida diretamente com a questão da dívida pública, porém, ao definir o populismo econômico e o protecionismo nacionalista como causas da crise na região, pressupõe implicitamente a mesma solução para a crise e para a dívida. Em outras palavras, a crise da dívida seria apenas uma das facetas de uma crise maior, originada na má gestão e interferência do Estado na economia; logo, o receituário para ambos seria o mesmo.

Dentro desta nova dinâmica econômica, os países, já sob governos constitucionais eleitos, adotaram a cartilha neoliberal imposta pelo Fundo Monetário Internacional (FMI) como condição para os processos de renegociação das dívidas durante a década de 1990. No entanto, a adoção de seguidos programas ortodoxos pautados por um ajuste fiscal que se encerra em si mesmo acirrou os conflitos socioeconômicos existentes no interior dos países latino-americanos. Houve um processo de fragilização dos países uma vez que a redução da participação estatal em termos gerais representou a diminuição de sua capacidade de se afirmar através de políticas econômicas e fiscais. Dentre as causas deste processo destacam-se: a menor capacidade de projeção do Estado; a dificuldade de manipulação dos mecanismos de ajuste existentes e; a sua inserção no mercado internacional em condições desfavoráveis.

\footnotetext{
${ }^{3}$ Destacam-se as ideias oriundas da escola austríaca (Hayek, von Mises), dos monetaristas estadunidenses (Friedman, Stigler) e da escolha pública (Buchanan, Olson). Tais ideias foram endossadas e disseminadas pelo governo estadunidense, pelo Fed, demais países do G7, presidentes dos maiores bancos internacionais e agências multilaterais ligadas às finanças.
} 
A dívida pública em particular ganhou peso ainda maior na condução das políticas de governo, submetendo as legislações e orçamentos nacionais à influência dos detentores de títulos públicos. Brasil e Equador não foram exceções à nova dinâmica. Ambos, a despeito de suas particularidades e diferentes formas de inserção no sistema internacional, passaram por ajustes neoliberais na década de 1990. Pode-se identificar uma persistência estrutural da primazia dos elementos financeiros no seio da evolução dos países, que se reflete na incapacidade de avançar no desenvolvimento social.

\section{ESQUEMA ANALÍTICO E APRESENTAÇÕES CONCEITUAIS}

Os processos históricos de endividamento dos países da América Latina possuem mais transversalidades do que particularidades. Seus inícios históricos datam do período imediato às independências e a evolução desde então é relativamente uniforme e sujeita à disponibilidade e ao interesse do capital internacional. A condicionalidade dos processos de desenvolvimento da região ao financiamento externo é marco da trajetória econômica do subcontinente (Ziliotto, 2011). Embora seja reducionista tratar os processos latino-americanos como bloco perfeitamente homogêneo, é possível aglutinálos de forma coerente como objeto de análise, uma vez observadas suas transversalidades. Logo, as unidades escolhidas - Brasil e Equador - são comparáveis não por seus aspectos materiais e imateriais, mas pela trajetória e desenvolvimento histórico similar e por sua inserção comum frente ao sistema financeiro internacional.

Assim, adota-se uma análise histórico-comparativa que compartilhará características apontadas por Mahoney e Rueschemeyer (2003), tais como: a realização de comparações sistemáticas e contextualizadas entre um número reduzido de casos similares e contrastantes; e a incorporação da estrutura temporal dos eventos nas explicações. Embora se trate de um método indutivo, não há pretensão de universalidade. Acreditase, entretanto, que a análise é replicável para países em situação estrutural similar, em especial da América Latina. 
O trabalho utiliza a dependência da trajetória de forma similar à proposta por Mahoney (2000; 2001), ou seja, como estrutura analítica (framework). O autor aponta que “(...) dependência da trajetória ocorre quando um evento histórico contingencial aciona uma sequência subsequente que segue um padrão relativamente determinístico"4 (Mahoney 2000, p. 535, tradução nossa).

Nos casos escolhidos, conforme indicado na figura 1, o acesso facilitado ao crédito internacional proveniente da reciclagem de petrodólares combinado à necessidade de autofinanciamento dos regimes militares são as condições históricas antecedentes. Já a opção pela via do endividamento externo é a escolha que desencadeia o padrão

Figura 1: Esquema analítico da dependência da trajetória

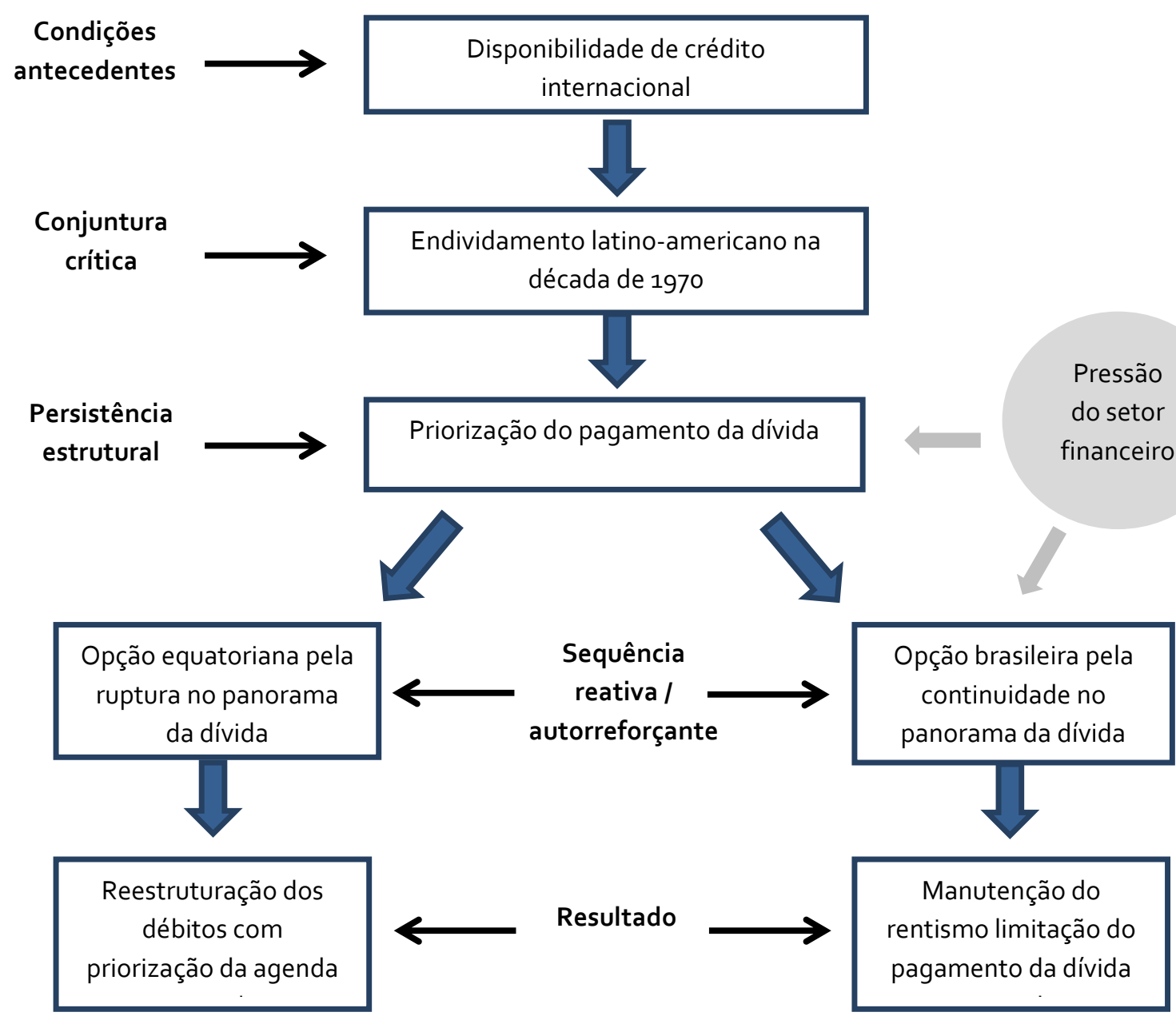

Fonte: Mahoney (2001, p. 113; 115). Elaboração própria.

${ }^{4}$ path dependence occurs when a contingent historical event triggers a subsequent sequence that follows a relatively deterministic pattern. 
relativamente determinístico de inversões financeiras na América Latina. Mahoney (2001, p. 112) sugere que após uma escolha em determinada conjuntura crítica torna-se progressivamente mais difícil retornar ao ponto inicial em que outras opções se encontram disponíveis, o que conduz a uma persistência estrutural. Entretanto, enquanto no Brasil seguiu-se uma sequência autorreforçante de eventos, no Equador a sequência de eventos teve caráter reativo, ou seja, que transformam ou revertem uma tendência anterior. Como consequência, cada país obteve um resultado diferente: manutenção dos privilégios do setor financeiro e limitação do pagamento da dívida social no Brasil e reestruturação dos débitos e priorização da agenda social no Equador.

Segundo Chesnais (1996), as finanças se alimentam por meio de dois mecanismos: a formação de capital fictício ${ }^{5}$ e as transferências de riqueza para a esfera financeira. Em ambos os casos o serviço da dívida pública é um importante mecanismo, responsável ainda por sujeitar os Estados a posições definidas pelos mercados e acentuar a hierarquização entre os países credores e devedores. O processo estabelecido por Chesnais (1996) é trabalhado por Harvey (2011) a partir do "nexo Estado-finanças", dinâmica em que o Estado é fomentador das estruturas de acumulação de capital enquanto se sustenta pelos aportes financeiros do mercado e por suas novas funções monetárias e financeiras.

O debate acerca da nomenclatura da dívida pública diverge conforme o escopo e a área de conhecimento do estudo em questão. Uma análise que aborde o tema através de uma ótica multidisciplinar demanda uma conceituação abrangente, mas que, ao mesmo tempo, limite questionamentos de origem taxonômica. Nesse sentido, será utilizada a definição oficialmente adotada por organizações internacionais, que a definem como "o montante em dívida das responsabilidades reais, e não contingentes, que exigem pagamento(s) de capital e/ou juros pelo devedor em algum(uns) momento(s) no futuro" (Panizza 2008, p. 4, tradução nossa) ${ }^{6}$.

\footnotetext{
${ }^{5}$ O motivo pelo qual determinado capital é fictício “(...) está no fato de que por detrás dele não existe nenhuma substância real e porque não contribui em nada para a produção ou para a circulação da riqueza, pelo menos no sentido de que não financia nem o capital produtivo, nem o comercial" (Carcanholo e Sabadini 2009, p. 43).

${ }^{6}$ the outstanding amount of those actual current, and not contingent, liabilities that require payment(s) of principal and/or interest by the debtor at some point(s) in the future.
} 
A forma de cálculo da dívida também é objeto de debate. A organização "Auditoria Cidadã da Dívida Pública" inclui, por exemplo, as rubricas refinanciamento e rolagem no cômputo da dívida. Nessa análise, o percentual do orçamento brasileiro destinado varia entre 40\% e 50\% durante o período 2002-2012 (Fattorelli, 2013). Outras visões, porém, destacam ser um erro incluir tais rubricas nesta conta, pois desta maneira ocorre uma confusão entre fluxo e estoque de endividamento, o que, metodologicamente, é um equívoco (Salvador, 2010). No cálculo de Espírito Santo e Mendes (2016), os percentuais variam entre $15 \%$ e $25 \%$ para o mesmo período.

\section{BRASIL E EQUADOR NO SÉCULO XXI}

Marques (2010) avalia que, desde o fim da ditadura militar, a economia brasileira se encontra sob uma nova ordem de dominação do rentismo em detrimento de políticas de desenvolvimento econômico e social. Verifica-se a privatização da receita e da capacidade de projeção do Estado brasileiro com a criação de um rígido arcabouço jurídico-institucional que garante o funcionamento da finança pública como uma válvula de transferência dos recursos públicos para agentes privados e/ou internacionais. Atualmente, o Brasil é o segundo país mais desigual entre os membros do G20 (Roberts, 2017), cuja explicação se encontra, em parte, nos mecanismos de desvio orçamentário em favor dos serviços da dívida, tais como as Desvinculações de Receitas da União (DRU) e a destinação integral do superávit primário ao pagamento da dívida, conforme estabelecido em lei.

A dívida brasileira não foge ao padrão das dívidas latino-americanas: é custosa, atrelada a ajustes macroeconômicos, de curto prazo e financiada em difíceis condições, com liquidez quase diária7 (Roberts, 2017). Embora parte da dívida seja continuamente refinanciada (rolagem da dívida), há custo imediato na forma de pagamentos de juros e amortizações. Os Relatórios Anuais da Dívida apontam que no biênio 2016-17 foi abatido

\footnotetext{
${ }^{7}$ Na prática, significa a transformação da dívida em moeda corrente constantemente, o que torna o título público brasileiro - e logo o Estado - mais vulnerável a oscilações de mercado.
} 
um total de $\mathrm{R} \$ 424,21$ bilhões, mais que o dobro do orçamento da pasta Educação para o mesmo período 8 .

A singularidade do caso brasileiro é a taxa de juros descolada da realidade internacional. A Grécia, por exemplo, ainda sem conseguir se recuperar da crise dos últimos anos e com relação dívida/PIB quase três vezes maior do que o Brasil, possui despesa com encargos e pagamentos de juros 30\% menor (Espírito Santo e Mendes, 2016). Desse modo, o argumento de que a taxa de juros é mais alta apenas para precificar o risco de calote não possui aderência à realidade, o que sugere a dívida pública como uma questão política, e não apenas técnica ${ }^{9}$.

Na década de 1990, as gestões de Fernando Henrique Cardoso (FHC, 1995-2002) foram capazes de estabilizar a economia brasileira com o Plano Real acompanhado pelo câmbio sobrevalorizado, altas taxas de juros e de um conjunto de medidas de caráter neoliberal consistente com as diretrizes do Consenso de Washington, bem como a redução do papel estatal na execução de políticas públicas e de desenvolvimento. A estabilização econômica alcançada se deu em bases estritamente econômicas e financeiras.

No ambiente externo, as sucessivas crises financeiras em outros países emergentes demandavam taxas de juros reais cada vez mais altas. O câmbio artificialmente valorizado e os déficits no primeiro mandato também contribuíram para o aumento da dívida. Mesmo com o início da política de superávit e a desvalorização da moeda no segundo mandato, a dívida continuou a subir. Contabilizada em $\mathrm{R} \$ 153,4$ bilhões em janeiro de 1995 a dívida pública federal passou para R\$881,1 bilhões em dezembro de 2002. Em termos relativos ao PIB, o aumento foi de 30\% para 57,4\% (Goldemberg e Prado 2003, p. 232-233).

Paralelamente, o crescimento econômico do período foi baixo, com queda no rendimento real do assalariado (Goldemberg e Prado, 2003). Se, por um lado, o Brasil se

\footnotetext{
8 Disponível em: <http://www.tesouro.fazenda.gov.br/documents/10180/269444/RAD_2016_pt-br.pdf/ec1dfc428088-49ad-9bb7-535a220307e6> e <http://www.tesouro.fazenda.gov.br/documents/10180/269444/ RAD+2017/73b6e764-0a77-4c99-9f79-3a3d9e7c5c1f>. Acesso em: 04/08/2018.

9 Um exemplo desse caráter político é o objetivo da Secretaria do Tesouro Nacional de aumentar a parcela de títulos pré-fixados, com menor prazo de vencimento, conforme consta no Plano Anual de Financiamento 2018. Disponível em: <http://www.tesouro.fazenda.gov.br/documents/10180/269391/PAF+2018/37056e6f-9cf0-423f-83528e1277acc2a8>. Acesso em: 04/08/2018.
} 
tornou atrativo a investidores a partir das políticas neoliberais; por outro, tais políticas acirraram os conflitos existentes na sociedade brasileira. A percepção de esgotamento do modelo neoliberal no Brasil pelas camadas mais populares da sociedade ensejou a possibilidade de mudança política no país.

Em 2003, com a ascensão à presidência do Partido dos Trabalhadores (PT), associado à esquerda política, assumiu-se uma perspectiva de revisão da prioridade dada aos interesses do setor financeiro. No entanto, o que se verificou foi a continuidade da agenda econômica anterior. Cumprindo o prometido na "Carta ao povo brasileiro", Lula (2003-2010) deu prosseguimento às políticas que vinham sendo adotadas no governo FHC, mantendo os pilares da macroeconomia.

O cenário internacional favorável, com aumento das receitas e dinamização do consumo interno, descortinava um leque de atuação político-econômica tornando-se um ponto de inflexão histórico. No entanto, com uma política fiscal ainda mais rigorosa, na presidência de Lula houve ampliação na inversão de valores para os serviços da dívida pública. Se o governo FHC foi marcado pelo aumento dos valores devidos e à estruturação de mecanismos para seu pagamento, o governo Lula reduziu os valores devidos por meio do aprofundamento de tais mecanismos.

Mesmo as medidas relativas ao tema não alteraram o quadro. A antecipação da dívida com o FMI em dezembro de 2005, por exemplo, anunciada como marco histórico do país teve caráter meramente eleitoral. Isso porque membros do FMI permaneceram como assessores do governo pautando a agenda através da pressão por medidas ortodoxas, tais como as metas de superávit fiscal. Ademais, a antecipação paga com parte das reservas internacionais é contraditória com a emissão de títulos no mesmo ano, em particular quando comparadas as taxas de juros praticadas pelo FMI - cerca de $4 \%$ - e dos novos títulos - entre $7,55 \%$ e $8,9 \%^{10}$. Na prática, a substituição dos papéis do FMI pelos novos papéis gerou aumento dos gastos com rolagem e pagamento de juros. Em outro momento, na esteira da crise de 2008 , em que os países reduziram seguidamente suas taxas de juros, o Brasil seguiu na contramão e subiu os juros a fim de sinalizar

\footnotetext{
10 Disponível em: <http://www.stn.fazenda.gov.br/hp/downloads/Informes_da_Divida/Financiamento_ Externo_ago.pdf>. Acesso em: 05/10/2018.
} 
credibilidade aos mercados financeiros. Somente em dezembro de 2008 o Banco Central deu início a uma política de redução da taxa de juros.

Embora a exigência de uma auditoria da dívida esteja presente na Constituição, a Comissão Parlamentar de Inquérito da Dívida Pública instaurada em 2009 foi engessada nas casas parlamentares, a despeito das indicações de irregularidades e ilegalidades (Cunha, 2013). No início de 2016, a presidenta Dilma Rousseff vetou a inclusão de uma proposta de auditoria da dívida pública que havia sido aprovada na Comissão de Finanças do Congresso e incluída no Plano Plurianual. Os argumentos utilizados foram o conflito de competências entre diferentes instâncias do governo e a transparência já existente na prestação de contas públicas.

Por uma perspectiva estritamente econômica, a existência da dívida pública não limita, a priori, os investimentos sociais. Dentre as receitas e despesas correntes, os gastos primários não necessariamente disputam espaço fiscal com os juros; no entanto, a excessiva parte destinada à dívida pública limita esforços que visem de uma redistribuição orçamentária menos inclinada ao rentismo. Em resumo, a política de continuidade adotada pelo Brasil privilegia rentistas credores dos papéis públicos que se tornam influenciadores das políticas monetária, fiscal e cambial.

Durante os governos Lula e parte dos governos Dilma, o momento de crescimento acelerado do PIB possibilitou aumento dos investimentos e melhoria de índices sociais, porém, a desaceleração da economia resultou em perda dos avanços conquistados ${ }^{11}$. A isso se atribuem diversas causas, com destaque para a análise heterodoxa de que o modelo de desenvolvimento econômico e social não seria sustentável com base no crescimento via consumo, que depende do constante aumento da renda, e ausência de mudanças estruturais.

A segunda causa dialoga com a ausência de iniciativas que alterassem de maneira significativa o impacto da dívida sobre as diferentes formas de desenvolvimento brasileiro. No esquema analítico da dependência da trajetória, a política de continuidade em relação à dívida pública configura uma "sequência autorreforçante" que,

\footnotetext{
11 O percentual da população vivendo em condição de extrema pobreza, por exemplo, retornou ao nível de 2006. Disponível em: <https: //apublica.org/2018/07/a-extrema-pobreza-voltou-aos-niveis-de-12-anos-atras-dizpesquisador-da-actionaid-e-ibase/>. Acesso em: 09/10/2018.
} 
progressivamente, torna mais difícil estabelecer políticas que revertam o quadro. Por sua vez, tal dinâmica limita o leque de possibilidades de desenvolvimento tanto social quanto econômico por restringir as opções de atuação do Estado.

Já o Equador possui histórico similar ao Brasil com o início de seu processo de endividamento no período de sua ditadura militar (1972-1979). A situação equatoriana foi agravada pela contínua turbulência política que dificultou quaisquer projetos de desenvolvimento do país. Em um dos pontos mais críticos, o Equador dolarizou oficialmente sua economia no ano 2000 a partir da combinação entre instabilidade política, desastres naturais, queda do preço do petróleo e dolarização informal da economia.

Segundo Onur Tas e Togay (2014), a dolarização teve impactos macroeconômicos positivos, sendo responsável pelo controle da inflação, maior crescimento do PIB e redução da incerteza inflacionária. Por outro lado, os autores reconhecem que a perda do principal mecanismo de política monetária tornou o Equador mais suscetível ao deficit fiscal e a flutuações no cenário internacional e, portanto, mais exposto ao peso de sua dívida.

De forma análoga ao caso brasileiro na década de 1990, a estabilização macroeconômica pós-dolarização foi realizada ao custo do arrocho social das camadas baixas e médias da população. Para Vernengo e Bradbury (2011), a dolarização foi uma extensão das políticas neoliberais iniciadas em 1992, que, por sua vez, tiveram como pano de fundo as reestruturações da dívida pública durante a década de 1980. Os autores associam o aspecto financeiro da neoliberalização no Equador à fuga de capitais que se seguiu e à redução da disponibilidade de meios de financiamento do país.

Não obstante a dolarização, nos anos anteriores à eleição de Rafael Correa persistiu a instabilidade política. De janeiro de 2000 a dezembro de 2006, seis nomes estiveram na presidência do país, entre presidentes eleitos, vices e juntas governamentais. Defendendo as bandeiras de inclusão de grupos politicamente excluídos e de reversão das políticas econômicas, Correa mobilizou significativas partes da sociedade civil equatoriana e a partir desta base foi capaz de promover algumas das mudanças a que se propunha. 
A chegada de Correa, da Alianza Patria Altiva y Soberana (PAIS), à presidência em 2007 representou, de fato, uma mudança estabilizadora nos rumos políticos. Gallegos (2011) identifica mudanças fundamentais como a nova Constituição, a introdução do ideal de "buen vivir", o afastamento dos Estados Unidos e a aproximação dos países da América Latina que permitem caracterizar o governo de Rafael Correa como pósneoliberal. Vidal (2017) aponta que a nova política equatoriana é encarada como sucesso ou fracasso conforme a perspectiva, sendo a principal crítica do autor o fato de que as mudanças não conduziram a uma reconfiguração na posição do Equador no sistema internacional, uma vez que reforçaram sua condição de exportador de produtos primários, em particular de petróleo. Já Ray e Kozameh (2012) fazem um balanço dos primeiros cinco anos da administração de Correa e concluem que o conjunto de políticas possibilitado pela liberação orçamentária a partir da auditoria da dívida alavancou tanto o desenvolvimento econômico quanto o social.

A nova Constituição, promulgada em 2008, deu início a uma série de transformações nas políticas econômica e fiscal do país. O texto da Carta reverteu a independência do Banco Central Equatoriano tornando-o parte do governo e submetendo suas decisões ao interesse público. Foram estabelecidos ainda requerimentos de liquidez para os bancos e imposto sobre saídas de capital, que auxiliaram no controle sobre a especulação e aumentaram a receita federal. Para Weisbrot, Johnston e Merling (2017, p. 10), esses foram os elementos que permitiram ao Equador dobrar o investimento social no período 2007-2015.

Paralelamente, em 09 de julho de 2007, Correa, instaurou a Comissão para a Auditoria Integral do Crédito Público (CAIC) com o objetivo de

examinar e avaliar o processo de contratação e/ou renegociação do endividamento público, a origem e o destino dos recursos e a execução dos programas e projetos financiados com a dívida interna e externa, com o fim de determinar sua legitimidade, legalidade, transparência, qualidade, eficácia e eficiência, considerando os aspectos legais e financeiros, os impactos econômicos, sociais e de gênero; regionais, ecológicos e sobre nacionalidades e povos (Equador 2007, p. 2, tradução nossa) ${ }^{12}$.

\footnotetext{
12 examinar y evaluar el proceso de contratación y/o renegociación del endeudamiento público, el origen y destino de los recursos y la ejecución de los programas y proyectos que se financien con la deuda interna y externa, con el fin de determinar su legitimidad, legalidad, transparencia, calidad, eficacia y eficiencia, considerando los aspectos legales y financieros, los impactos económicos, sociales, de género; regionales, ecológicos, y sobre nacionalidades y pueblos.
} 
A partir das descobertas da auditoria, o Equador decretou moratória de dois tipos de títulos - os Global Bonds 2012 e 2030 - que representavam aproximadamente 65\% da dívida externa do país. A moratória ocorreu no ápice da crise financeira, apenas algumas semanas após o colapso do grupo Lehman Brothers, momento em que o setor financeiro internacional se encontrava em aguda crise. O default equatoriano fez o valor de seus títulos despencar, o que oportunizou um programa de recompra dos títulos ao preço médio de 30 centavos por dólar.

O resultado da manobra foi a imediata redução no impacto da dívida sobre o orçamento do Equador. Os custos com serviço da dívida em relação ao Produto Interno Bruto (PIB) foram reduzidos em mais de 50\% (Vidal, 2017). Com a redução do pagamento da dívida, o Equador reverteu maior fatia do orçamento para investimentos sociais, mormente saúde, educação e habitação. A Figura 2 mostra a evolução dos gastos sociais comparada ao valor destinado ao pagamento de serviços da dívida.

Figura 2: Comparativo dos gastos sociais e da dívida pública no Equador

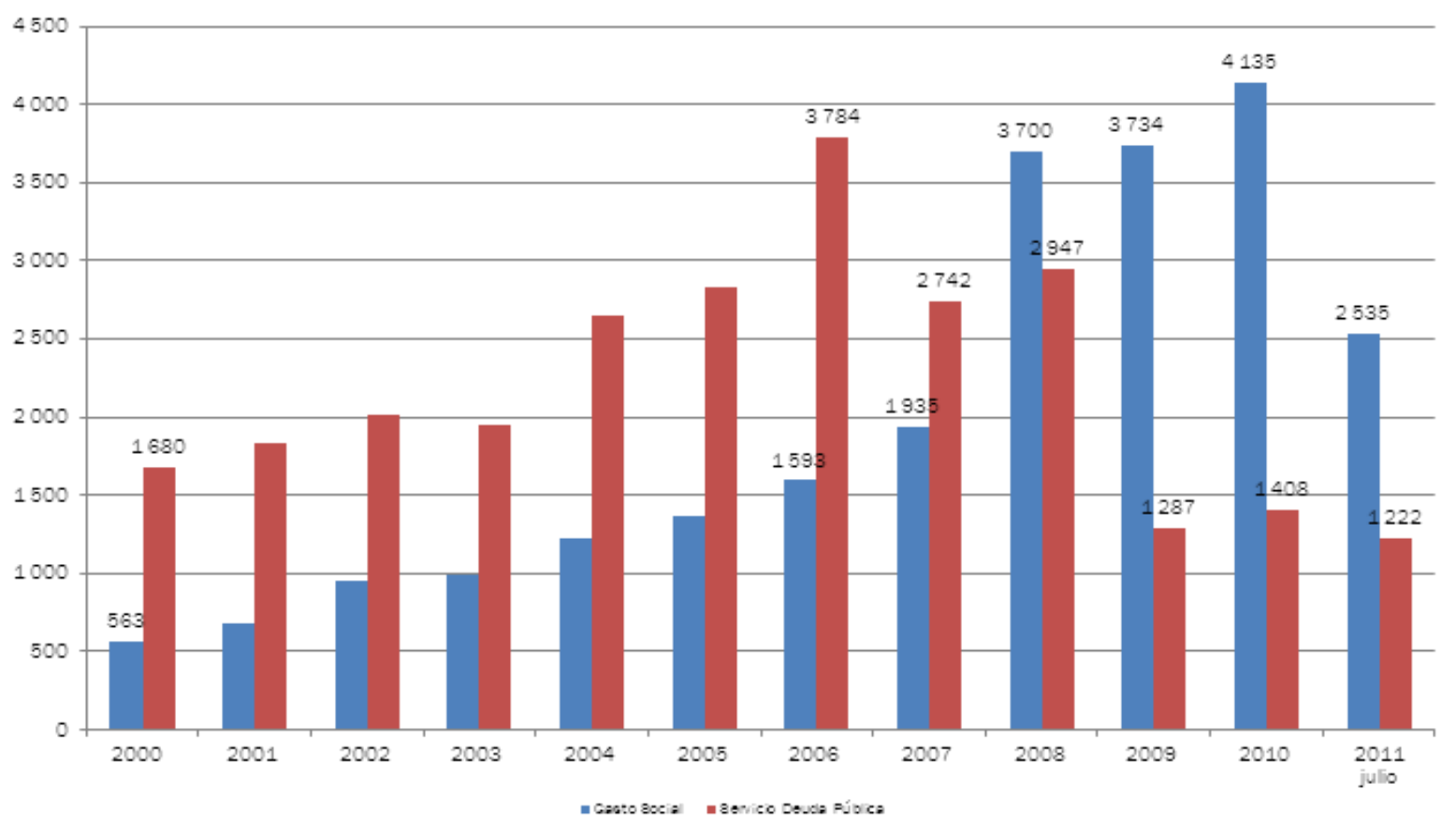

Fonte: Banco Central Equatoriano (BCE).

A redução do custo com a dívida não apenas possibilitou o aumento do investimento social, como abriu margem para um novo endividamento em termos mais 
vantajosos, com foco em acordos bilaterais e afastamento do FMI e do Banco Mundial. A reestruturação da dívida foi funcional para a renovação da atuação do Estado na economia e na sociedade. Conciliou, de um lado, o crescimento da economia, cujo PIB cresceu em média 4,75\% durante o período pós-crise de 2008-2012 (Ray e Kozameh, 2012); de outro, a melhoria das condições de vida e de índices sociais, como a redução do coeficiente Gini de 0,55 para 0,47 e o maior percentual de investimento na educação de nível superior da América Latina (Weisbrot, Johnston e Merling, 2017).

Importante notar que os principais riscos apontados pelo mercado - fuga de capitais e exclusão do mercado financeiro internacional - não se concretizaram. O Equador continuou com acesso a crédito em organismos multilaterais (tais como o Banco Interamericano de Desenvolvimento e o Fundo Latino-Americano de Reservas) e em acordos bilaterais, principalmente com a China. Em 2014, o Equador foi "readmitido" como tomador de crédito e emissor de títulos públicos junto a bancos privados internacionais, já com sua classificação de risco (rating da Standard \& Poor's) no mesmo nível anterior à auditoria (Vidal, 2017).

Verificou-se no país uma política de ruptura em relação à dívida pública. Fugindo à tendência de continuidade de um padrão determinístico estabelecido por Mahoney (2001), a presidência de Correa deu início a uma "sequência reativa", um encadeamento de eventos e políticas que produziu resultados diferentes daqueles obtidos pelos demais países endividados da América Latina - como o Brasil - com primazia da agenda social sobre as inversões financeiras.

Percebe-se que os governos do PT no Brasil e do PAIS no Equador partiram de premissas e concepções diferentes em relação às propostas para a dívida pública. No caso brasileiro o PT assumiu desde antes da chegada ao poder um caráter conciliador que, na prática, reafirmou a dívida pública como um dos eixos centrais da política econômica. Tal centralidade é evidenciada no pequeno aproveitamento das potencialidades do momento econômico na medida em que os avanços econômicos e sociais foram limitados pela "disputa" com políticas que priorizam aspectos financeiros em detrimento de aspectos sociais. Nesse caso, a priorização do pagamento da dívida pública é instrumental para a reprodução do rentismo no Brasil. 
A despeito das condições similares, o governo de Correa se afirmou sobre uma intenção "revolucionária" que posteriormente foi executada de forma apenas reformista. Não houve qualquer movimento que sugerisse uma revolução de facto na estrutura política ou no modo de produção, mas passos no sentido de uma reorganização da função do Estado. Por meio de mudanças na estrutura estatal e sua atuação na economia, o governo Correa foi capaz de seguir um curso distinto do padrão estabelecido na América Latina.

\section{CONSIDERAÇÕES FINAIS}

O cenário internacional favorável do início da década passada propiciou melhoria nos dados sociais, destacadamente via programas de transferência de renda. Não obstante, a inércia no panorama da dívida pública evidenciou os limites do modelo brasileiro, conjuntural e oscilante conforme os ventos da economia internacional, diante da maior sustentabilidade do modelo equatoriano, baseado em uma mudança estrutural orçamentária em favor dos investimentos sociais.

Importante observar que a centralidade da dívida pública na estruturação do Estado, isto é, a organização do Estado em favor do sistema da dívida e não sua utilização como mecanismo de desenvolvimento tem consequências que transbordam as questões financeiras. Na América Latina, o peso da dívida é elemento restritivo do avanço em diversas esferas: ecológica, social e econômica. O reconhecimento de que a manutenção de uma política de continuidade em relação à dívida pública é limitadora da América Latina é um importante passo no sentido de priorizar aspectos sociais em detrimento de financeiros. O caráter político, e não técnico, da primazia dos serviços da dívida torna o problema um assunto a ser trabalhado além dos aspectos econométricos, contábeis etc. Faz-se necessária a inserção da temática em debates políticos, sociais e de disputa pela narrativa.

Mecanismos de reestruturação da dívida pública - como a auditoria equatoriana não são soluções definitivas, uma vez que existem outras formas de sequestro do 
orçamento público que apenas podem ser revertidos com uma mudança estrutural, já que fazem parte da infraestrutura do sistema atual. Porém, tais mecanismos se mostram ferramentas úteis e uma auditoria detalharia o quadro real da dívida pública brasileira, o que teria potencial de mitigar eventuais gastos indevidos e com isso possibilitar maior projeção do Estado brasileiro.

As diferentes premissas que conduziram os governos analisados impactaram a forma de atuação de cada um. Enquanto no Brasil desde o início adotou-se uma política de conciliação, no Equador uma política de enfrentamento foi levada a cabo e posteriormente acomodada. Na prática, isso resultou em continuidade do panorama da dívida pública no Brasil e cisão no caso do Equador.

Até o presente momento houve esforços limitados em abordar aspectos teóricos e metodológicos sobre a temática da dívida pública ${ }^{13}$, o que reforça a necessidade de estudos avançados. De forma complementar, é necessária uma aproximação entre o panorama teórico e a realidade dos países latino-americanos. Assim, o trabalho buscou argumentar em favor de um diálogo entre a bibliografia existente, seu aprofundamento a partir dos casos de Brasil e Equador e o diálogo dos variados aspectos que compõem a temática da dívida pública.

\footnotetext{
${ }^{13}$ Algumas dessas abordagens podem ser identificadas em Weber (2008).
} 
REFERÊNCIAS BIBLIOGRÁFICAS

BRESSER-PEREIRA, Luiz Carlos. A crise da América Latina: Consenso de Washington ou crise fiscal? Revista pesquisa e planejamento econômico, 21(1), p. 3-23, 1991

CARCANHOLO, Reinaldo; SABADINI, Mauricio. Capital fictício e lucros fictícios, Revista da Sociedade Brasileira de Economia Política, v. 24, p. 41-65, 2009.

CHESNAIS, François. A mundialização do capital, São Paulo, Xamã, 1996

EICHENGREEN, Barry; HAUSMANN, Ricardo. Exchange rates and financial fragility. NBER Working Papers, n. 7418, 1999

Equador. Decreto Executivo no 472/2007, 2007

ESPÍRITO SANTO, Marcos Henrique; MENDES, Áquilas. O fundo público e o capital portador de juros: o papel da dívida pública brasileira no capitalismo contemporâneo. Pesquisa \& Debate, 27(1), p. 25-44, 2016.

FATTORELLI, Maria Lucia. Auditoria Cidadã da Dívida Pública: Experiências e métodos, Brasília, Inove, 2013.

GALLEGOS, Franklin. Fragmentación, reflujo y desconcierto: movi-mientos sociales y cambio político en el Ecuador (2000-2010), 2011. In: REBON, Julián; MODONESI, Massimo (Org.). Una década en movimiento: luchas populares en América Latina en el amanecer del siglo XXI, Buenos Aires, Prometeo Libros, 2011.

GOLDEMBERG, José; PRADO, Luiz Tadeu. Reforma e crise do setor elétrico no período FHC. Tempo Social, 15(2), p. 219-235, 2003.

HARVEY, David. O enigma do capital e as crises do capitalismo, São Paulo, Boitempo, 2011.

MAHONEY, James. Path-dependent explanations of regime change: Central America in comparative perspective. Studies in Comparative International Development, 36(1), p. 111-41, 2001.

MAHONEY, James. Path dependence in historical sociology. Theory and Society, 29(4), p. $507-48,2000$.

MAHONEY, James; Rueschemeyer, Dietrich. Comparative historical analysis in the social science, Nova lorque, Cambridge University Press, 2003. 
MARQUES, Rosa Maria; FERREIRA, Mariana. (Org.). O Brasil sob nova ordem, São Paulo, Saraiva, 2010.

ONUR TAS, Bedri Kamil; TOGAY, Selahattin. Efectos de la dolarización oficial en una pequeña economía abierta: el caso de Ecuador. Investigación económica, 73(290), p. 51-86, 2014.

PANIZZA, Ugo. Domestic and external public debt in developing countries. UNCTAD Discussion Papers, n. 18, 2008.

RAY, Rebecca; KOZAMEH, Sara. Ecuador's economy since 2007. Washington, [s.n], 2012.

ROBERTS, Michael. Brazil: The debt dilemma. Pesquisa \& Debate, 28(2), p. 6-13, 2017.

SALVADOR, Evilásio. Fundo público e seguridade social no Brasil, São Paulo, Cortez Editora, 2010.

SCHONERWALD, Carlos Eduardo; VERNENGO, Matías (2007). Foreign exchange, interest and the dynamics of public debt in Latin America. Department of Economics Working Paper Series, n. 2, p.1-16, 2007.

STRANGE, Susan. States and markets, Londres, Pinter Publishers, 1988.

VERNENGO, Matias; BRADBURY, Mathew. The limits to dollarization in Ecuador: lessons from Argentina. Journal of World-Systems Research, 17(2), p. 447-62, 2011.

VIDAL, Lorenzo. The political economy of Ecuador's external debt default. International Review of Applied Economics, p. 1-23, 2017.

WEBER, Gabriela. Sobre la deuda ilegítima: Aportes al debate, Quito, [s.n.], 2008.

WEISBROT, Mark; JOHNSTON, Jake; MERLING, Jake. Decade of reform: Ecuador's macroeconomic policies, institutional changes, and results, Washington, Center for Economic and Policy Research, 2017

WILLIAMSOM, John. Latin American adjustment, Washington, Institute of International Economics, 1990.

ZILIOTTO, Guilherme Antonio. Dois séculos de dívida pública: a história do endividamento público brasileiro e seus efeitos sobre o crescimento econômico (18222004), São Paulo, Editora Unesp, 2011.

ZWAN, Natascha van Der. Making sense of financialization. Socio-economic Review, 12(1), p.99-129, 2014. 